Arab World English Journal (AWEJ) Volume 12. Number2 June 2021

Pp. 424-435

DOI: https://dx.doi.org/10.24093/awej/vol12no2.29

\title{
The Principles of Economy in Word-Formation in Functional Styles of English
}

\section{Saurbayev Rishat Zhurkenovich}

Foreign Philology Department, Faculty of Humanities and Social Sciences

Sultanmakhmut Toraighrov University, Pavlodar, Kazakhstan

\section{Zhetpisbay Aliya Kozhamuratkyzy}

Pavlodar pedagogical university, Pavlodar, Kazakhstan

Higher School of Humanities

\section{Demessinova Galina Khatipovna}

Foreign Philology Department, Faculty of Humanities and Social Sciences

Sultanmakhmut Toraighrov University, Pavlodar, Kazakhstan

Kulbayeva Baglan Tasbulatovna

Pavlodar pedagogical university, Pavlodar, Kazakhstan

Higher School of Humanities

\section{Vafeev Ravil Aisovich}

Foreign Philology Department, Faculty of Humanities and Social Sciences

Sultanmakhmut Toraighrov University, Pavlodar, Kazakhstan

Received: $3 / 24 / 2021$

Accepted: 6/2/2021

Published: 6/24/2021

\section{Abstract.}

The article is devoted to studying the principles of the language economy of modern English wordforming. The most productive ways of word-formation are highlighted, illustrating the tendency of the language to compress nominative units. In the system of English word-formation, the most effective ways to save speech are affixal word formation, word composition, and conversion. Due to the considerable potential of these methods of word formation, the vocabulary of the English language has such qualities as the richness of vocabulary, functionality, and economy. The main aim of the study is to consider the principles of word-formation in the modern English language through word-forming models represented by the concepts of length and depth of the generating word. The authors of the article explore the mechanism of the principle of the economy through the consideration of the ideas of "mental energy", "word-forming energy", and "pronouncing energy". There are issues that attempt to answer; how does the principle of economy work in the English language - its word formation? What are the significant models of word formation in modern English? The findings indicate that there are active processes in the wordformation of the English language, which can cause the formation of new words without changing the length and depth of the generating term expanding the possibilities of word composition and conversion.

Keywords: abbreviation, acronyms, economy, English language, functional styles, mental energy, morpheme, phoneme, principle, pronouncing energy, speech economy, word-formation, word-forming energy

Cite as: Zhurkenovich, S. R., Kozhamuratkyzy, Z. A., Khatipovna, D. G., Tasbulatovna, K. B., \& Aisovich, V. R. (2021). The Principles of Economy in Word-Formation in Functional Styles of English . Arab World English Journal, 12 (2) 424-435. DOI: https://dx.doi.org/10.24093/awej/vol12no2.29 


\section{Introduction}

Despite the variety of names, the essence of language economy is as follows: it is a universal category inherent in all languages of the world, characterized by the desire to avoid high physiological and psychological costs in speech production and manifested at all levels of the language system.

The problematic nature of the study of language economy consists mainly in the uncertainty of its status and the mechanism of influence on the language system. Many linguists have studied the problem of language economy in their researches and works, and their attitude to it is not always the same. Some recognize it as the leading law of language development Martine (2009), Zipf (1949), while others believe that economy occur in language. Still, not all changes occurring in the language system explained by this law Zipf (1949), de Saussure (2013), Sepir (2007), Koseriu(1992)), and still, others deny the role of the economy in the development and functioning of language Schleicher (1860), Budagov(1977). The concept of economy is closely related to the idea of redundancy. The redundancy of a language expression is that more language resources are used to transmit the primary meaning than it is necessary. Nevertheless, it seems possible to consider that the principles of economy and redundancy are not directly opposed but rather complement each other.

The relevance includes the fact that language economy is today one of the most active processes that influence the development of the English language, its driving force, operating with a wide variety of techniques and units at the lexical and syntactic levels of the language system. In many cases, we are talking about neological formations in English word-forming that acquire stability over time. However, the problem of language economy in modern English has not yet received comprehensive coverage in either domestic or foreign linguistics (Goipova, Gofurov, Qodirov 2020) Yi Xu, Santitham Prom-on 2019).

Many questions related to the study of the mechanisms of the process of abbreviation, elliptization, and the existence of various types of abbreviated structures, their status, and their role in the system of the modern English language, continue to remain unresolved. Also, we can say about the peculiarities of their spelling and, phonetic design, grammatical characteristics and the possibilities of the formation of derivatives.

In connection with the preceding, the topic of this article, devoted to the study and analysis of the English texts, which manifest the principle of economy, leading to a reduction in the mental stress of communicants, is relevant. And it is essential from the point of view of the scientific and practical significance of the problem. The purpose of this article is how the principles of the economy work in the English language - in its word formation.

The hypothesis of this study is the assumption that in the English language, the effect of the law of linguistic economy at the lexical and syntactic levels manifests in the formation of various types of abbreviated units. They have unique semantic, structural, and functional characteristics, which leads to their high productivity, reproducibility, recognizability. The following methods of scientific research used in the investigation: the practice of continuous sampling in collecting actual language material, the descriptive and distributive practice of 
linguistic analysis, the practice of component analysis, the method of contextual analysis, the quantitative approach.

\section{Literature Review}

The economic structure of the language, which permeates its entire system, is striking even to the linguistically untrained observer. Many linguists have repeatedly noted this property. The semantic structure of the word results in the compactness and economy of speech. Implications have a more significant amount of information contained in the semantic system than words have.

Martine (2009) put forward the principle of the economy as the basis of his linguistic description, based on the fact that the constant contradiction between the needs of human communication and his desire to minimize his mental and physical action considers as the driving force of language changes. Here, as in many other cases, human behavior is subject to the law of least effort. The person is wasting their strength only to the extent necessary to achieve a particular goal.

Zvyagintsev (1972) criticized Martinet for his unique approach to the principle of language economy. He believed that some techniques to the study of certain language phenomena deserve special attention. Still, not all of them can provide a comprehensive description of the language in all its aspects.

The issue of saving speech efforts considers in the works of Zipf (1949), who studied speech as a natural environment for the manifestation of economy, as an aspect of communicative behavior that governs the principle of speech economy. The researcher, Vandries (1939), describes speech economy within the phonetic and phonological changes. The language economy has traditionally worked at the phonological level. Vandries also believed that it could also work at the level of words and syntax.

The famous English linguist Sweet (2015) justifies the use of speech economy as idleness and inertia of the speaker, and then he identifies two trends in the economy; the omission of redundant sounds and the ease of transition from one sound to another, which leads to the fusion and assimilation of sounds.

Leopold (1930) argues on the question of the economy of speech that the tendency to clarity encourages the speaker to strive to be understood. Still, the innate tendency of man given by nature to save any of his efforts: physical and moral, and in particular in language, leads to the economy of speech.

Tauli (1958), who strongly influenced the views of Martinet, put forward the position of the paradigmatic and syntagmatic economy. He believes that language evolution can determine five driving forces: (1) the tendency to clarity, (2) the tendency to simplicity and economy of effort, (3) the emotional impulse, (4) the aesthetic tendency, (5) the social impulse. 
The Kazakh linguists Amrenov, Tekzhanov, Omarov (2013a) considered the economy's performance in syntactic constructions. Kazakh linguists advanced the idea of complication of the sentence in the plane of semantics and reduction of the structure of the clause (2013b); also, it covered the problem of compression of the syntactical unit in work by Saurbayev (2013c).

The concept of "Word-Forming Energy", further (WFE) should consist of two inseparable parts that reflect the dialectical unity of the two sides of the word - it is the meaning (the plane of content), and it is the sound complex (the plane of expression). The first of these parts can represent a certain amount of mental (mental) energy further (ME) expended by the speaker to set the meaning of a word by identifying the minimum semantic units that make up it, i.e., morphemes. The amount of mental energy expended by the speaker for this process is the first component, "Word-Forming Energy", further (WFE). It is natural to conclude that this amount of ME depends on the number of morphemes in the word or, using the term proposed by Moskovich (1969), on the depth of the word.

The second part of the concept of WFE, respectively, can be represented as a certain amount of pronouncing (physical) energy further (PE), spent by the speaker on the articulation of the word in words. Since, according to the assumption of Stepanov (1966), for the speaker, the minimum unit of speech is a syllable and not a separate phoneme. Again, it is natural to assume that the amount of pronouncing energy (PE) depends on the number of syllables in a word, i.e., on its length. Thus, WFE=ME+PE.

For this work, (Moskovich 1969) conclusions are very crucial. First, the maxima of the length and depth of words in natural languages coincide with the amount of human RAM (Random Access Memory) and do not exceed $7 \pm 2$ morphemes and syllables in support of Yngve's (1966), hypothesis. Second, when using a language in all its functions, there is a consistent tendency to avoid exceeding these maxima and use words of optimal size.

\section{Methods}

The main principle of the study is synchronic, which is implemented in synthesis with a diachronic approach. In the course of the work, we used the following ways: descriptive research method aimed at empirical research and description of the word-forming process in modern English, the comparative method which used in the study, considers the average depth of a word in the Old English word-forming, the use of the transformational approach is connected with the possibility of certain transformations to identify differences in semantic and syntactic nature between the components of word-forming elements. In the study, we also use component analysis, which is considered a discrete analysis, the competence of which includes: 1) decomposition of lexical meaning into semes; 2) their matrix description; 3) opposition of the semantic level to the linguistic one.

\section{Findings}

An optimal word should have a root morpheme (R0) to identify a language as a means of communication for expressing a real meaning, a derivational morpheme (D) for describing a lexical-grammatical sense, and a relational morpheme (R) for representing the syntactic relations 
of a word given with other words and sentences. Thus, the optimal word structure for any language should look like this:

$$
\mathrm{R} 0+\mathrm{D}+\mathrm{R} 1
$$

As you know, the relational morpheme is not characteristic of English words, and the optimal structure of the English word should be recognized as a two-part R0+D model, that is, a two-morpheme formation, which is most often two-syllable.

However, according to the data of Greenberg (1960), the average depth of the English word in speech is 1.68 morphemes, and the average length, according to Fuchs (1957) - 1.351 syllables (in frequency, monosyllabic words takes the first place $-70 \%$, the second two-syllable words-20\%).

Therefore, the average depth and length of a modern English word in speech is less than the optimal model, i.e., they are economical.

If we compare the average depth of a word in Old English, according to Greenberg (1960, p. 68), it is 2.12 morphemes. Its average depth in a modern English word will be significantly lower than in the compared language. It allows us to conclude that in English word-formation for several centuries, there is a pronouncing tendency to reduce the depth. The length of the word, that is, to save word-forming energy. It is primarily the result of the loss of inflections (Old Eng. word drincan, $\rightarrow$ Middle Eng. word drinken $\rightarrow$ in Modern Eng. word drink), as well as the assimilation of borrowed words by analogy with the original model (French word crier Eng. cry), simplification (Old Eng. hläf weard $\rightarrow$ in Middle Eng. hlöford $\rightarrow$ in Modern Eng. lord). and other processes in terms of diachrony. However, its manifestation considers in terms of synchrony, namely, in the action of some word-forming processes in the modern English language, which helps us create new economic words. First, of course, it is necessary to consider those processes in which the formation of a derived word is accompanied by a quantitative reduction, i.e., a reduction in the length and depth of the generating term and, accordingly, a cost reduction (WFE).

1. Abbreviation, or reduction, for example:

to dub (a film) $\leftarrow$ to double,

lube $\leftarrow$ lubricant,

pop $\leftarrow$ popular

fam $\leftarrow$ family

Abbreviated words in English tend to appear primarily in conversational styles, from literary colloquial to jargon. The result from the high frequency of use of the complete polysyllabic prototype and the associated natural desire of the speaker to save their efforts. Acronyms and compound words arise in newspaper-journalistic, military, and scientific-technical styles also as a result of high frequency, penetrating from them into other styles:

It should note that since the depth and length of words in English do not coincide, the resulting shortening of the size of the generating word often leaves a deformed morpheme, for example: 
to double - one morpheme and two syllables;

to $d u b$ - one syllable and a deformed morpheme;

popular - three syllables and two morphemes;

pop - one syllable and a deformed morpheme:

2. Reverse word-formation, conversion the linguistic basis of which is the law of analogy. For example:

To edit $\leftarrow$ editor

To enthuse $\leftarrow$ enthusiasm

To chauff $\leftarrow$ chauffeur (French borrowing)

In these cases, verb formation is the result of assimilation of the originally borrowed noun, the structure of which is reinterpreted by analogy with the existing model, and the final part of the root word motivated as a word-forming suffix is rejected. As a result, the length is reduced, and the depth of the generating word is deformed.

More numerous in modern English are cases of the reverse formation of verbs from complex nouns of the type $\mathrm{N}+\mathrm{N}$, where the second base derived, for example:

to baby $\leftarrow$ to baby-sit

to blood $\leftarrow$ transfuse blood transfusion

In these cases, the reverse word-formation results from a false analogy with the homonymous parasynthetic model $(\mathrm{N}+\mathrm{N})+e r$. For example: a first-nighter.

As a result, both the length and depth of the original word reduced, but unlike the previous cases, morpheme deformation does not occur:

a baby-sitter - four syllables and three morphemes;

to baby-sit - three syllables and two morphemes;

blood-transfusion-four syllables and four morphemes;

to blood-transfusion-three syllables and three morphemes.

3. Word-compounding:

a best-seller, a crash-helmet;

war-damaged; factory-packed, etc.

Complex words are compressed phrases, and their economy is shown in their wholeformedness in comparison with the separate-formedness of phrases, for example:

a best-seller - a book that sells best,

war-damaged-damaged during the war.

However, the economy of the compound word is not uniformly preferable to all functional styles. In the style of scientific prose, for example, in most languages, including English and Russian, they avoid compressing all the morphemes that express a scientific concept in one word, and the central unit becomes a phrase. For example: in English-end dump body in Russian-a dump truck tipping over backward, and in German Hinterkipperaufbau following the productivity in all German styles of the corresponding models of complex and super-complex words. 
It is interesting to trace from the point of view of the principle of the economy the further development of the term-phrase: because of the high frequency of its use, it is reduced, turning into an abbreviation, and sometimes into a quasi-word:

NATO - North Atlantic Treaty Organization

Radar-radio detection and ranging, jato - get-assisted take-off, etc.

4. Insert word-formation (Blending):

cinerama $=$ cine $(m a)+($ pano $)$ rama,

walkathon = walk(mar)athon,

transistor - trans $($ fer $)+($ re $)$ sistor, etc.

It is interesting to note that the elements that make up such words consider are not morphemes but only fragments of the two derived words. In recent years, inserts have become widely used in the scientific and technical style as a means of more economical expression of complex content:

transistor, composition, metaplastic, etc.

The inserts in the American journalistic style acquire a particular stylistic color, often as a means of irony, for example:

Republicrat (a person who votes for Republicans, then for Democrats):

salariat (low-paid employees);

paytriotism (patriotism for selfish purposes).

5. Substantiation in (conjunction with the ellipse):

a postal $\leftarrow$ a postal order,

finals $\leftarrow$ final examinations, etc.

As a result of frequent use, the second element of the phrase (noun) disappears, and the first (adjective) takes on nominative functions.

All the five cases of WFP savings discussed above, illustrates the reduction of the cost of PE. At the same time, the identification of a derived word requires a large number of ME in comparison with the generating word, since each newly formed word is larger than the generating word, in terms of the number of steps or cycles of generation (according to the applicative model of Shaumyan):

to double $(\mathrm{R} 1 \mathrm{R} 3 \mathrm{O}) \leftarrow$ to dub $(\mathrm{R} 1 \mathrm{R} 1 \mathrm{R} 3 \mathrm{O})$,

editor $(\mathrm{R} 2 \mathrm{O}) \leftarrow$ to edit $(\mathrm{R} 1 \mathrm{R} 2 \mathrm{O})$,

postal order $(\mathrm{R} 3 \mathrm{R} 2 \mathrm{O}+\mathrm{R} 2 \mathrm{O}) \leftarrow$ postal $(\mathrm{R} 2 \mathrm{R} 3 \mathrm{R} 2 \mathrm{O})$.

This conclusion is in full accordance with the law of conservation and transformation of energy, according to which, when a certain amount of one point disappears, a certain amount of another energy appears in its place: WFE2 $=($ PE2 $<$ PE1 $)+($ ME2 $>$ ME1 $)$. (1) The next group of word-forming processes, in which the effect of the principle of economy observed consists of processes resulting from a new derived word formed without any external changes, i.e., without changing the length and depth of the generating word.

1. Conversion rate: 


$$
\begin{aligned}
& \text { to fault } \leftarrow \text { a fault } \\
& \text { to final } \leftarrow \text { a final } \\
& \underline{\text { a must }} \leftarrow \text { must etc. }
\end{aligned}
$$

Conversion allows you to denote in one word what otherwise in the language can express as a whole phrase. In our opinion, these examples illustrate the economy in the word-forming process: to treat favorably or to treat with favor.

2. Semantic word-formation, which results in new meanings of generating words:

to land on the water,

to comb = scour a place, comb a place,

disk = a gramophone record,

façade = outward appearance,

to freeze $=$ to stabilize (wages, etc.)

In word-formation during conversion, as in the semantic plane, word-forming processes can cause the formation of new words without changing the length and depth of the generating term with an unexpressed derivative, but only with an increase in the number of generation cycles:

a fault (R2O) to fault (R1R2O), to freeze $-1 \times(\mathrm{R} 1 \mathrm{O}), \leftarrow 2 \times(\mathrm{R} 1 \mathrm{R} 1 \mathrm{O})$

(one syllable and one morpheme, but two bars of the word generator).

In these cases, the WFE is spent only on identifying the new meaning of the derived word and not on its additional articulation in comparison with the generating word:

$$
\text { WFE2 }=(\text { PE2 }=\text { PE1 })+(\text { ME2ME1 }) \text {. }
$$

\section{Discussion}

When discussing the law of economy, linguists often use the phrase "language cancels something", "Language gets rid of something", "language strives to get rid of something", "language tries to escape of ponderous speech structures", etc. Of course, language itself as a system of signs does not have its own will and purpose.

It is the speakers themselves who unconsciously strive to reduce the necessary minimum in communication - and the forces that are spent on the pronunciation-speech effort, speech energy, and the time it takes to transmit certain information.

The law of saving speech time, especially in a conversational style, has situational and social limitations. Therefore, it often causes severe complaints from the zealots of the purity of the literary norm.

But the law of saving language resources is the most controversial among linguists. Indeed, according to this law, many languages have "extra" grammatical categories and forms, such, for example, from the point of view of some linguists, the category of gender, since gender in modern languages does not have its semantics. But does this mean that the so-called "genderless" languages, such as English, Armenian, and Turkic, are better and more economical than 
languages with a developed category of genders, such as Russian, German, and others? Is it even acceptable to measure the optimality of the language system from the perspective of another language? Taking into consideration the precariousness of such statements, Russian linguist Budagov seriously criticized the law of economy.

The principle of economy is universal because it acts as one of the main reasons for changes in all languages. This principle also manifests its versatile role from the perspective. Namely, it finds its expression at all levels of the language system. The means of implementing this principle at each level have their specifics and are considered separately.

The conducted research allowed us to identify the main word-forming models of the English language. It results in affixal formations, which have the most significant productivity in all parts of speech since they have passed a long way of historical development. Such methods as word derivation and word composition give the main number of newly formed words. The study of effective practices of making new terms will contribute more to the identification of external and internal laws, as well as trends in the development of the word-forming process.

Word-forming methods and means have different activities. Currently, conversion formations are the most active in the creation of new words.

The ability to build and understand derived units leads to a genuine knowledge of the language, fluency in constructions not only of the syntactic but also of the morphological level.

The economy in the structuring of the language system is one of the linguistic laws based on which all languages work. However, the differences between them are expressed in one or another way. Such a universal law cannot without reason be considered one of the most general linguistic universals applicable to any language, as well as to any of its aspects.

Language development and functioning are regulated by various processes occurring in the language, but the degree of their distribution is different. Some of them are universal -they appear in all or almost all languages, while others have a national character. One of the universal processes of this kind can represent a language economy.

In modern word-formation, there is a tendency to move from statics - how ready-made words constructed to dynamics - how they formed, what means and prerequisites are available for this. Comparing the obtained two series of formulas, we can draw the following conclusions:

For identifying a new word, no matter how it works, a large amount of ME is always spent than what was required for the title of the generating word since each new word has a new meaning.

The economy of WFE in the formation of new words with the help of abbreviation, reverse, and insertion methods of word-formation, substantiation, conversion, and semantic word-formation, only PE should take into account. The amount of PE either decreases (to dub to 
double) when forming a new word or remains unchanged in cases of unspoken derivation (to favor $\leftarrow$ a favor $)$.

\title{
Conclusion
}

The purpose of this study is to reveal and describe word-formation as fully and comprehensively as possible through the prism of the principle of linguistic economy, which brings to life particular linguistic processes and phenomena. The enrichment of the vocabulary of any language depends on the extralinguistic conditions in which it functions and develops. The development of the language is constantly improving, and words and phrases are undergoing semantic changes. Words change into a different lexical and grammatical category, changing and rethinking the meaning of words.

Changes in the meaning of words lead to a change in the function of the word, to the making of new words with the help of existing words and with the word-forming means: abbreviation, or reduction, conversion, blending, word-compounding, substantivization. In every living language, the process of replenishing it with new words never stops. They are created by word-formation accordingly.

The language characterized by the desire to save speech resources, which provides informational compression, gives information succinctly through a compressed structure. The law of language economy considers as one of the primary laws of language development, and it is universal because of it is present at every level of the language system.

Depending on this, the principle of economy of speech is implemented through different specific means, and the result for all is the economy of speech effort, time for pronouncing and transmitting the message. One of the principles of language economy realized through the wordformation, which causes active processes in the development of the word-stock under intensifying communications in modern English.

\begin{abstract}
About the Authors:
Rishat Zhurkenovich Saurbayev, a Ph.D., is a professor of the Foreign Philology Department, Faculty of Humanities and Social Sciences, Sultanmakhmut Toraighrov University, Pavlodar, Kazakhstan. The author has 200national and international publications. His scientific interests lie in comparative and contrastive linguistics, social linguistics, semantics.

ORCIDiD https://orcid.org/0000-0003-1419-7361
\end{abstract}

Zhetpisbay Aliya Kozhamuratkyzy, a Ph.D., is an assistant professor of the Higher School of Humanities of Pavlodar Pedagogical University. She defended her doctoral dissertation on the topic "Syntactic combination and structural models of verbal phrases" (2010). The author has 40 publications. Her research interests include syntax, comparative and contrastive linguistics.

ORCID : https://orcid.org/0000-0002-3126-5242

Demessinova Galina Khatipovna, a Ph.D., is an assistant professor of Foreign Philology Department, Faculty of Humanities and Social Sciences, Sultanmakhmut Toraighrov University, Pavlodar, Kazakhstan. She published 85 papers in national and international scientific journals. 
Her research interests include typological and comparative linguistics, translation studies.

Kulbayeva Baglan Tasbulatovna a Ph.D. is an assistant professor of the Higher School of Humanities of Pavlodar Pedagogical University. The author published about 60 papers. Her scientific interests include pragmalinguistics, sociolinguistics, general linguistics, issues of the development of multilingualism.

Ravil Aysavich Vafeev a Doctor of Philology, Professor of the Department of Foreign Philology of Pavlodar Toraighrov University. He made a significant contribution to the study of bilingualism in Russia and CIS countries. His research interests include the following: sociolinguistics, psycholinguistics, methodology, problems of bilingualism and multilingualism. He has 312 published scientific papers, including articles, monographs, textbooks and teaching aids. Under his scientific supervision, 21 doctoral dissertations defended.

\section{References}

Budagov R. A. (1977) What is the development and improvement of the language? Moscow Publishing House "Science."

Coseriu E.(1992) Linguistic Competition: Elements of the Speaking Theory, Biblioteca Romanica Hispanica. Madrid.

De Saussure F. (2013) About Course in General Linguistics. Bloomsbury Academic An imprint of Bloomsbury Publishing Plc.

Fuchs V. (1957). The mathematical view of word-formation. Theory of message submission, pp. 226-235.

Goipova S., Gofurova S., Qodirov S. (2020) The Economy Principle in Languages. International Journal of Advanced Research in Science, Engineering and technology. Vol. 7, Issue 1, pp.12435- 12439

Greenberg J. (1960). The quantitative approach to the morphological classification of languages. International Journal of American Linguistics. 26(3) pp. 178-197.

Martine A. (2009). Fundamentals of general linguistics. Publisher: LIBROKOM, Moscow.

Moskovich V. A. (1969). Depth and length of words in natural languages. Voprosy Jazykoznanya. (Issues of Linguistics) 6, Publisher: "Academy of Science of the USSSR"pp. 17-33.

Leopold W. (1930). Polarity in language, in Curme volume in linguistic studies, Baltimore, Waverly Press.

Sapir E. (2007) Language. BiblioBazaar Charleston, South Carolina.

Saurbayev R.Zh. Tekzhanov K.Kh., Ergaliyev K.S, Amrenov A.D. \& Omarov N.R. (2013a). To the Problem of Delimitation of the Expanded Sentence as an Independent Syntactic Category in Modern Linguistics) Life Science Journal; 10 (12s), 464-474.

Saurbayev R.Zh. Tekzhanov K.Kh., Ergaliyev K.S, \& Amrenov A.D. (2013b). On the Issue Structure-Semantic and Predicative Features of Semi-Composite Sentences and Their Functions in the Bounds of Paradigmatic Syntax. Life Science Journal; 10 (4), 10421050.

Saurbayev R. Zh. (2013c), The Tagseme as a Component of Structural-Semantic Complexification of the Sentence, Middle East Journal of Scientific Research. 16 (3) Publications. 432-436. DOI: 10.5829/2013.16.03.11699 
Schleicher A. (1860) Die Deutsche Sprache. (The German Language) Stuttgart: J. G. Cotta, vii. Stepanov Yu. (1966). Fundamentals of linguistics. Publishing House, "Prosveshchenie," Moscow.

Sweet H. A (2015). History of English Sounds from the earliest period, Oxford: Oxford University Press.

Tauli V. (1958). The structural tendencies of language: "Suomalainen Tiedeakatemia" Helsinki.

Vendryes J. (1939). Parle par économie, in Mélanges de linguistiques offert à Charles Bally, Genéve, George \& C. I. e, 49-62. (a book)

Yi Xu, Santitham \& Prom-on. (2019) Economy of Effort or Maximum Rate of Information? Exploring Basic Principles of Articulatory Dynamics. Frontiers in Psychology, Language Sciences 2019 pp. 1-22. | https://doi.org/10.3389/fpsyg.2019.02469

Yunyev. V. I. (1966). On the correlation of oral and written forms of the language. Foreign languages at higher schools, 1966, 2, - 17.

Zipf G. K. (1949). Human Behavior and the Principle of Least Effort, Cambridge, Massachusetts, Addison-Wesley Press

Zvegintsev V. (1972). New in linguistics, Publishing House "Progress," Moscow. 